\title{
Congenital hypothyroidism: treat children but don't forget their parents
}

\author{
Luca Chiovato $^{1}$ and Stefania Bargagna ${ }^{2}$ \\ ${ }^{1}$ Department of Endocrinology, University of Pisa, Via Paradisa 2, 56124 Pisa, Italy and ${ }^{2}$ Stella Maris Scientific Institute, Institute of Developmental \\ Neurology, Psychiatry and Educational Psychology, University of Pisa, Pisa, Italy \\ (Correspondence should be addressed to L Chiovato, Department of Endocrinology, University of Pisa, Via Paradisa 2, 56124 Pisa, Italy; Email: \\ l.chiovato@endoc.med.unipi.it.)
}

Congenital hypothyroidism $(\mathrm{CH})$, detected in 1:3500 to 1:4000 newborns world-wide, is one of the most common preventable causes of mental retardation if treated early (1). In the 1970 s neonatal screening programmes were started to guarantee detection and treatment from the first weeks of life. Prior to the onset of screening, when clinical diagnosis was commonly delayed, the neurodevelopmental prognosis in $\mathrm{CH}$ children was poor. A clear inverse relationship was evident between age at start of treatment and intelligence quotient (IQ), the worst outcome (75\% with IQs $<80$ ) being observed in those infants diagnosed at the ages of 6 and 9 months (2). Screening programmes have been extremely successful in the detection and early treatment of infants with $\mathrm{CH}$, and in preventing the serious neuropsychological sequelae of this condition. Although neuropsychological follow-up studies in general have been favourable, slightly lower IQs compared with unaffected controls have been reported, particularly in the most severely affected infants $(1,2)$. Some follow-up programmes report good psychometric outcomes, with IQs similar to controls (3-5) and no apparent impediment in school performances (3). Other reports indicate a mild decrease in IQs of $\mathrm{CH}$ infants in spite of early substitution treatment (6-9). The latter studies also report poorer motor skills $(6,10,11)$, defective language abilities (12) and learning problems in school (13). A 1996 metanalysis of literature data, which included 675 patients and 570 controls in North America and Europe, showed a trend toward lower IQs and slightly poorer motor skills in $\mathrm{CH}$ patients compared with controls (14). Pooling of data showed a significant deficit of the mean IQ of 6.3 points $(95 \%$ confidence interval: 4.7-7.8). A common problem of these studies is the difficulty in controlling for appropriate modulating influences of neuropsychological development such as genetic background, socio-economic status, cultural level of the family and education burden. While false positive cases, siblings, matched or unselected normal children have been used as controls (14), unaffected identical twins raised in the same family would be the best control when complex functions such as intelligence are investigated. Two genetically identical twins, one of whom had thyroid agenesis and the other who was unaffected were described in this Journal in 1997 (15). In spite of early (4th week of life) and adequate Lthyroxine $\left(\mathrm{L}-\mathrm{T}_{4}\right)$ therapy $(9 \mu \mathrm{g} / \mathrm{kg}$ per day), the $\mathrm{CH}$ twin showed IQ scores that were in the normal range but lower compared with the unaffected twin. At the age 7 of years the deficit in total IQ scores was 7 points (108 vs 115), a figure similar to that estimated in the metanalysis of literature data.

Several risk factors for the eventual outcome of the neuropsychological development in early-treated $\mathrm{CH}$ have been evaluated. These include: (i) pretreatment serum $\mathrm{T}_{4}$ concentration; (ii) neonatal skeletal maturation; (iii) aetiology of $\mathrm{CH}$; (iv) age at start of treatment; (v) starting $\mathrm{L}^{-\mathrm{T}_{4}}$ dose; (vi) adequacy of substitution treatment in the first 2 years of life and even afterwards; (vii) socio-economic class of the family. Most follow-up studies found a significant correlation between cognitive development and pretreatment serum $\mathrm{T}_{4}(4,6,8-10$, 16). In a multicentre survey in the UK (16), the relationship between IQ and serum $\mathrm{T}_{4}$ level at diagnosis was discontinuous with a threshold of $3.3 \mathrm{mg} / \mathrm{dl}$ $(42.8 \mathrm{nmol} / \mathrm{l})$. Below this level, a 10-point IQ deficit was observed as compared with control subjects of similar social class. Above this threshold, children were unlikely to suffer more than a 5-point deficit. A skeletal development at the time of diagnosis $\leqslant 36$ weeks of gestation (12) or an area of the knee epiphysis $<0.05 \mathrm{~cm}^{2}$ (9) were both found to be associated with significantly lower IQs compared with control groups. Overall, the severity of foetal-neonatal hypothyroidism, defined by skeletal maturation at diagnosis and/or pretreatment serum $\mathrm{T}_{4}$, is the most important independent risk factor for the eventual neuropsychological outcome (14), partly due to an effect on brain development determined prenatally. Small amounts of maternal $\mathrm{T}_{4}$ pass the placenta (17), but it is difficult to believe that this limited maternal supply of $\mathrm{T}_{4}$ is sufficient in most cases of severe $\mathrm{CH}$. In keeping with these observations, several studies found that children with severe $\mathrm{CH}$ due to thyroid agenesis achieve significantly lower IQs compared with hypothyroid children with thyroid ectopy who display some degree of residual thyroid function $(6,10,18)$. 
Treatment variables also play a role in the cognitive development of children with $\mathrm{CH}$. The duration of neonatal hypothyroidism that occurs between delivery and the restoration of euthyroidism with therapy depends on both the age at starting treatment and the initial dose of $\mathrm{L}-\mathrm{T}_{4} . \mathrm{T}_{4}$ half-life appears to be shorter in the neonate, so that maternally transferred $\mathrm{T}_{4}$ levels fall rapidly (17). A significant negative correlation between age at start of treatment and neuropsychological outcome was found in early follow-up studies reporting the initial results of screening programmes (19). Development quotient scores of infants treated later than 50 days of age were below the normal mean (19). No such relationship has been reported in more recent surveys $(9,16)$, probably due to a general improvement in the screening procedures which resulted in earlier diagnosis and treatment of $\mathrm{CH}$ in the majority of affected children. Depending on the initial dose of $\mathrm{L}^{-\mathrm{T}_{4}}$, neonatal serum $\mathrm{T}_{4}$ and thyrotrophin (TSH) levels may take several weeks to rise to the normal range. In the US (20) higher starting doses of $\mathrm{L}^{-\mathrm{T}_{4}}(10-15 \mu \mathrm{g} / \mathrm{kg}$ per day) have been used to treat children with $\mathrm{CH}$ than in Europe $(5,16,21)$ and have been associated with a shorter time to achieve euthyroidism. The Quebec group (9) reported that infants with severe $\mathrm{CH}$, defined by low serum $\mathrm{T}_{4}$ levels and retarded skeletal maturation, who had been treated with an initial dose of $\mathrm{L}_{-} \mathrm{T}_{4}$ of $6 \mu \mathrm{g} / \mathrm{kg}$ per day beginning at a mean age of 5 weeks had a mean IQ at the age of 12 years that was 15 points lower than that of infants with less severe $\mathrm{CH}$. In a subsequent study by the same group (22), infants with severe $\mathrm{CH}$ were treated at a median age of 14 days with a starting dose of $12.1 \mu \mathrm{g} / \mathrm{kg}$ per day (median). At 18 months of age these severely affected $\mathrm{CH}$ children had a development quotient similar to that of infants with less severe hypothyroidism, who served as controls (22). The authors concluded that earlier treatment with a higher starting dose of $\mathrm{L}_{-} \mathrm{T}_{4}$ eradicated the gap in IQ scores between children with severe $\mathrm{CH}$ and those with the moderate form of the disease. It is worth emphasising that in this study the mean serum $\mathrm{T}_{4}$ concentration of infants treated with a higher dose of $\mathrm{L}_{-} \mathrm{T}_{4}$ was supraphysiological in the first few months of life, while serum tri-iodothyronine $\left(\mathrm{T}_{3}\right)$ levels were within the normal range at all times. Clinical signs of thyroid hormone excess or unduly advanced bone maturation were not observed in the Quebec study, but evidence from other reports suggests that higher starting doses of $\mathrm{L}-\mathrm{T}_{4}$ lead more commonly to behaviour problems reflecting anxiety, social withdrawal and poor concentration $(2,7)$. Thus, in the absence of randomised controlled studies comparing the effects on longterm outcome of the higher and lower doses of $\mathrm{L}-\mathrm{T}_{4}$, the use of initial dosages greater than $8-10 \mu \mathrm{g} / \mathrm{kg}$ per day should probably be restricted to those $\mathrm{CH}$ infants with extremely low $(<3 \mathrm{mg} / \mathrm{dl})$ pretreatment serum $\mathrm{T}_{4}$. Suboptimal treatment in the first and second year of life $(3,8)$, a time-period when the brain is critically dependent on $\mathrm{T}_{4}$ for normal development, may also negatively affect the neuropsychological outcome of $\mathrm{CH}$ children. Using linear multiple regression analysis and controlling for socio-economic status and pretreatment serum $\mathrm{T}_{4}$ concentration, a follow-up study in Norway (8) found that at 2 years of age $19 \%$ of the variance in mental development scores was due to treatment variables (combinations of serum $\mathrm{T}_{4}$ and TSH during the first year and bone age at 1.5 years). At 6 years of age, $35 \%$ of the variance in verbal IQ could be attributed to treatment variables: initial $\mathrm{L}-\mathrm{T}_{4}$ dose, mean serum $\mathrm{T}_{4}$ concentration in the first year and a combined measure of serum $\mathrm{T}_{4}$ and TSH during the second year (8). Even at the age of 15 or 16 years improvement in thyroid control by adequate substitution treatment was associated with a significant improvement in psychometric test scores (23). The socio-economic state of the family also has a significant impact on mental development $(16,19)$. This is evident both in infants with severe $\mathrm{CH}$ and in those with less severe hypothyroidism (16).

In this issue of the European Journal of Endocrinology Salerno et al. (24) report the intellectual outcome at 12 years of age of 40 children with $\mathrm{CH}$ detected by neonatal screening and treated at a mean age of 28 days with a standard initial dose of $\mathrm{L}_{-} \mathrm{T}_{4}(25 \mu \mathrm{g} /$ day; $6.8 \pm 1.8 \mu \mathrm{g} / \mathrm{kg}$ per day). Similar to some previous studies $(3-5)$ the mean full-scale IQ score of $\mathrm{CH}$ children did not significantly differ from that of their siblings used as controls. However, the mean performance IQ was significantly lower, suggesting minimal brain damage. Within the performance score, the items significantly affected were picture completion, block design and object assembly, which are considered to have a high spatial loading. Thirteen patients $(32 \%)$ in the present cohort showed definitely low IQ scores $(<80)$, significantly lower than those found in other patients and in unaffected siblings. Confirming the results of previous reports, low IQ scores were associated with a lower pretreatment serum $\mathrm{T}_{4}$ concentration $(4,6,8-10,16)$, thyroid agenesis $(6,10,18)$, less adequate treatment, probably due to poor compliance from the second year of life onwards $(3,8,23)$, and lower familial IQs (10). In our opinion these findings again emphasise the need for earlier initiation of treatment (within the first 2 weeks of life) and for a higher starting dose of $\mathrm{L}_{-} \mathrm{T}_{4}$, with the goal of shortening the duration of postnatal hypothyroidism. A specific effort is also recommended to improve the adequacy of $\mathrm{L}^{-\mathrm{T}_{4}}$ substitution and to ameliorate compliance to treatment. As suggested by the New England Congenital Hypothyroidism Collaborative (23), hormonal values should be monitored monthly as well as 2 weeks after any change in $\mathrm{L}^{-} \mathrm{T}_{4}$ dosages at least during the first year of life. Monitoring should then be continued three or four times a year through adolescence. The measurement of serum TSH, free $\mathrm{T}_{4}$ and possibly free $\mathrm{T}_{3}$ is recommended, and the dose of $\mathrm{L}-\mathrm{T}_{4}$ should be adjusted to maintain serum TSH concentrations in the normal range (18).

A new aspect of the present paper is the careful 
evaluation of the parental attitude to their children's disease. Most previous studies on early-treated children with $\mathrm{CH}$ report cognitive, motor and linguistic development, but do not specifically address the affective relationship between parents and affected children. Congenital diseases such as $\mathrm{CH}$ may result in a sense-ofguilt in the parents and in frustration due to the loss an idealised 'perfect' child. $\mathrm{CH}$ is a chronic disease associated with the need for continuous medical therapy and frequent monitoring. It is also a latent disease, because $\mathrm{CH}$ manifests with few clinical signs that are nicely controlled by substitution therapy but might result in impaired growth, neurologic deficits or mental retardation later in life. Parental worries and anxiety consequent to the birth of a baby with a congenital, chronic and possibly invalidating disease might be projected on the child, producing emotional distress, poor self-confidence and an anxious or depressed behaviour (25). In the Salerno et al. study (24), interviews with parents of $\mathrm{CH}$ children showed that the diagnosis of $\mathrm{CH}$, the perspective of endless treatment, and the need for frequent assessments had deleterious effects on their psychological well-being. Three educational-affective attitudes were identified in the parents: (i) $38 \%$ of them showed appropriate coping with the emotional distress and a good attitude toward rearing the child and toward the therapeutic programme; (ii) the majority $(51 \%)$ reacted with anxiety resulting in overstimulation of the child and strict compliance to therapy; (iii) a small minority (11\%) completely refused the disease showing poor attention to the emotional well-being of their child and poor compliance to treatment. The three types of personality profiles were distributed equally between children with low or normal IQs, indicating that their influence on poor cognitive performances was minor. Interestingly enough the fact that overstimulation and control were the most frequent parental attitudes might explain why in the present study $\mathrm{CH}$ children with normal IQs performed better than their siblings on the verbal tests. While the latter finding might be reassuring for the cognitive outcome of $\mathrm{CH}$ children, the high frequency of incorrect psychological attitudes observed in parents strongly suggests that the follow-up of $\mathrm{CH}$ children should include an evaluation of the parent-child affective relation. Psychological counselling of parents might be mandatory in most families of $\mathrm{CH}$ children.

\section{Acknowledgements}

This work was supported by grants from the National Research Council (CNR Rome, Italy): Target Project Biotechnology and Bioinstrumentation, Grant 91.01219, PF70; Target Project: Prevention and Control of Disease Factors (FATMA), Grant 93.00689, PF41; Target Project Ageing, Subproject Gerontobiology, Grant 93.00437, PF40; EEC Stimulation Action-Science Plan Contract SC1-CT91-0707.

\section{References}

1 Lafranchi S. Congenital hypothyroidism: A newborn screening success story? The Endocrinologist 19944 477-486.

2 Dattani M \& Brook CGD. Outcomes of neonatal screening for congenital hypothyroidism. Current Opinion in Pediatrics 19968 389-395.

3 New England Congenital Hypothyroidism Collaborative. Elementary school performance of children with congenital hypothyroidism. Journal of Pediatrics 1990116 27-32.

4 Simons WF, Fuggle PW, Grant DB \& Smith I. Intellectual development at 10 years in early treated congenital hypothyroidism. Archives of Diseases in Childhood 199471 232-234.

5 Ilicki A \& Larsson A. Psychological development at 7 years of age in children with congenital hypothyroidism: Timing and dosage of initial treatment. Acta Paediatrica Scandinavica 199180 199-204.

6 Kooistra L, Laone C, Vulsma T, Schellekens JMH, van der Meer JJ \& Kalverboer AF. Motor and cognitive development in children with congenital hypothyroidism: A long term evaluation of the effects of neonatal treatment. Journal of Pediatrics 1994124 903-909.

7 Rovet JF \& Ehrlich RM. Long-term effects of L-thyroxine therapy for congenital hypothyroidism. Journal of Pediatrics 1995126 380-386.

8 Heyerdahl S. Treatment variables as predictors of intellectual outcome in children with congenital hypothyroidism. European Journal of Pediatrics 1996155 357-361.

9 Glorieux J, Dussault J \& Van Vliet G. Intellectual development at age 12 years of children with congenital hypothyroidism diagnosed by neonatal screening. Journal of Pediatrics 1992121 581-584.

10 Rovet JF, Ehrlich RM \& Sorbara DL. Neurodevelopment in infants and preschool children with congenital hypothyroidism: etiological and treatment factors affecting outcome. Journal of Pediatric Psychology 199217 187-213.

11 Fuggle PW, Grant DB, Smith I \& Murphy G. Intelligence, motor skills and behaviour at 5 years in early-treated congenital hypothyroidism. European Journal of Pediatrics 1991150 570574.

12 Rovet J, Ehrlich R \& Sorbara D. Intellectual outcome in children with fetal hypothyroidism. Journal of Pediatrics $1987110700-$ 704.

13 Simons WF, Fuggle PW, Grant DB \& Smith I. Educational progress, behaviour, and motor skills at 10 years in early treated congenital hypothyroidism. Archives of Diseases in Childhood 199777 219222.

14 Derken-Lubsen G \& Verkerk PH. Neuropsychologic development in early treated congenital hypothyroidism: Analysis of literature data. Pediatric Research $199639561-566$.

15 Bargagna S, Chiovato L, Dinetti D, Montanelli L, Giachetti C, Romolini E, Marcheschi M \& Pinchera A. Neuropsychological development in a child with early-treated congenital hypothyroidism as compared with her unaffected identical twin. European Journal of Endocrinology 1997136 100-104.

16 Tillotson SL, Fuggle PW, Smith I, Ades AE \& Grant DB. Relation between biochemical severity and intelligence in early treated congenital hypothyroidism: a threshold effect. British Medical Journal $1994309440-445$.

17 Vulsma T, Gons MH \& De Vijlder JJM. Maternal fetal transfer of thyroxine in congenital hypothyroidism due to a total organification defect or thyroid agenesis. New England Journal of Medicine $198932113-16$

18 Chiovato L, Giusti L, Tonacchera M, Ciampi M, Mammoli C, Lippi F, Lapi P, Bargagna S, Dini P, Ferretti G, Marcheschi M, Cesaretti G, Saggese G, Fenzi GF, Pfanner P \& Pinchera A. Evaluation of L-thyroxine replacement therapy in children with congenital hypothyroidism. Journal of Endocrinological Investigation 199114 957-964.

19 Illig R, Largo RH, Qin Q, Torresani T, Rochiccioli P \& Larsson A. Mental development in congenital hypothyroidism after neonatal screening. Archives of Diseases in Childhood 198762 10501055 . 
20 Fisher DA. Management of congenital hypothyroidism. Journal of Clinical Endocrinology and Metabolism 199172 523-529.

21 Touati G, Leger J, Toublanc JE, Farriaux JP, Stuckens C, Ponte C, David M, Rochiccioli P, Porquet D \& Czernichow P. A thyroxine dosage of 8 micrograms $/ \mathrm{kg}$ per day is appropriate for the initial treatment of the majority of infants with congenital hypothyroidism. European Journal of Pediatrics 1997156 94-98.

22 Dubuis J-M, Glorieux J, Richer F, Deal CL, Dussault JH \& Van Vliet G. Outcome of severe congenital hypothyroidism: Closing the development gap with early high dose levothyroxine treatment. Journal of Clinical Endocrinology and Metabolism 199681222 227.

23 New England Congenital Hypothyroidism Collaborative. Correlation of cognitive test scores and adequacy of treatment in adolescents with congenital hypothyroidism. Journal of Pediatrics $1994124383-387$.

24 Salerno M, Militerni R, Di Maio S, Bravaccio C, Gasparini N \& Tenore A. Intellectual outcome at 12 years of age in congenital hypothyroidism. European Journal of Endocrinology 1999141 105-110.

25 Stawski M, Auerbach JG, Barash M, Lerner Y \& Zimin R. Behavioural problems of children with chronic physical illness and their siblings. European Journal of Childhood and Adolescent Psychiatry 19976 20-25.

Received 28 April 1999

Accepted 3 May 1999 